\title{
Do wild suids from Ndumo Game Reserve, South Africa, play a role in the maintenance and transmission of African Swine Fever to domestic pigs?
}

\author{
Cynthia Mapendere ${ }^{1}$, Ferran Jori ${ }^{2}$, Eric ETTER ${ }^{2}$, and Jan Helenus Ferguson ${ }^{1}$ \\ ${ }^{1}$ University of Pretoria \\ ${ }^{2}$ CIRAD
}

October 22, 2020

\begin{abstract}
In Southern Africa, the African Swine Fever (ASF) sylvatic cycle presents a permanent threat for the development of the pig farming industry. Warthogs (Phacochoerus africanus) and bushpigs (Potamochoerus larvatus), wild reservoirs of ASF are present in Ndumo Game Reserve (NGR), located in Northern KwaZulu Natal Province in South Africa and within $30 \mathrm{~km}$ of the locations of endemic ASF outbreaks in Mozambique where sylvatic disease transmission has been implicated. To assess if wild suids represent a risk of ASF virus spillover to domestic pigs in the neighbouring community, transect counts and fence patrols were conducted and camera traps were deployed in NGR to estimate wild suid abundance and incursions outside NGR boundaries. We searched for Ornithodoros ticks in 35 warthog burrows distributed across different NGR areas. Pig farmers $(\mathrm{n}=254)$ surrounding Mathenjwa Community were interviewed to gather information on interactions between domestic and wild suids and the occurrence of ASF. We conclude that NGR has established populations of bushpigs and warthogs, estimated at 5 and 3-5 individuals $/ \mathrm{km} 2$ respectively. Both species move out of the reserve regularly ( 15.4 warthogs/day and 6.35 bushpigs/day), with a significant increase of movements during the dry season. Some farmers observed warthogs and bushpigs as far as 8 and $19 \mathrm{~km}$ from the reserve respectively, but no direct wild-domestic suids interactions nor any ASF outbreaks were reported. In addition, no soft ticks were found among the 35 warthog burrows. The absence of ticks in warthog burrows from NGR and the absence of reported outbreaks and familiarity with ASF in the surrounding farming area, suggest that a sylvatic cycle of ASF is at present unlikely in NGR. However, further research should be undertaken to confirm this by surveying a larger number of warthog burrows and monitoring potential antibodies in warthogs from NGR and domestic pigs in the neighbouring community.
\end{abstract}

Do wild suids from Ndumo Game Reserve, South Africa, play a role in the maintenance and transmission of African Swine Fever to domestic pigs?

Mapendere C. ${ }^{a}$, Jori F. ${ }^{b, c, ~ d}$, Etter E.M.C ${ }^{b, c, ~ e ~ a n d ~ F e r g u s o n ~ J . W . H ~}$

a. Centre for Environmental Studies, Department of Geography, Geoinformatics and Meteorology, University of Pretoria, South Africa

b. CIRAD, UMR Animal, Santé, Territoires, Risque et Ecosystèmes (ASTRE), Montpellier, France

c. ASTRE, University of Montpellier, CIRAD, INRA, Montpellier, France

d. Mammal Research Institute, Department of Zoology and Entomology, University of Pretoria, South Africa

e. Department of Production Animal Studies, Faculty of Veterinary Sciences, University of Pretoria, South Africa

\section{Summary}


In Southern Africa, the African Swine Fever (ASF) sylvatic cycle presents a permanent threat for the development of the pig farming industry. Warthogs (Phacochoerus africanus) and bushpigs (Potamochoerus larvatus ), wild reservoirs of ASF are present in Ndumo Game Reserve (NGR), located in Northern KwaZulu Natal Province in South Africa and within $30 \mathrm{~km}$ of the locations of endemic ASF outbreaks in Mozambique where sylvatic disease transmission has been implicated. To assess if wild suids represent a risk of ASF virus spillover to domestic pigs in the neighbouring community, transect counts and fence patrols were conducted and camera traps were deployed in NGR to estimate wild suid abundance and incursions outside NGR boundaries. We searched for Ornithodoros ticks in 35 warthog burrows distributed across different NGR areas. Pig farmers $(\mathrm{n}=254)$ surrounding Mathenjwa Community were interviewed to gather information on interactions between domestic and wild suids and the occurrence of ASF. We conclude that NGR has established populations of bushpigs and warthogs, estimated at 5 and $3-5$ individuals $/ \mathrm{km}^{2}$ respectively. Both species move out of the reserve regularly (15.4 warthogs/day and 6.35 bushpigs/day), with a significant increase of movements during the dry season. Some farmers observed warthogs and bushpigs as far as 8 and $19 \mathrm{~km}$ from the reserve respectively, but no direct wild-domestic suids interactions nor any ASF outbreaks were reported. In addition, no soft ticks were found among the 35 warthog burrows. The absence of ticks in warthog burrows from NGR and the absence of reported outbreaks and familiarity with ASF in the surrounding farming area, suggest that a sylvatic cycle of ASF is at present unlikely in NGR. However, further research should be undertaken to confirm this by surveying a larger number of warthog burrows and monitoring potential antibodies in warthogs from NGR and domestic pigs in the neighbouring community.

Key words: African swine fever, bushpigs, domestic pigs, warthogs, sylvatic cycle, South Africa

\section{Introduction}

In Southern Africa, warthogs (Phacochoerus africanus ) and bushpigs (Potamochoerus larvatus) are considered as potential wild reservoirs of African Swine Fever (ASF). Warthog is found in open savannah habitats in most of Sub-saharan Africa and their densities range from 1-10 individuals $/ \mathrm{km}^{2}$ in protected areas (Cumming, 1975). The bushpig is mainly distributed in forested areas of eastern, southern and western central Africa with densities ranging from 1-10 individuals $/ \mathrm{km}^{2}$ in protected areas (Venter, Ehlers Smith, \& Seydack, 2016). ASF is a highly infectious and hemorrhagic disease affecting exclusively domestic and wild suids, a significant threat to the pig industry worldwide (S Costard, Mur, Lubroth, Sanchez-Vizcaino, \& Pfeiffer, 2013). In Africa, the virus is maintained in two epidemiological cycles: the sylvatic cycle, involving warthogs and bushpigs, and the domestic cycle involving domestic pigs. The disease can be transmitted by direct contact with an infected animal, its body parts or its secretions, or indirectly through fomites or contaminated food (Chenais, Ståhl, Guberti, \& Depner, 2018). Warthogs do not become viraemic, apart from a brief period as young warthog piglets, and thus do not transmit the disease directly (Plowright, 1981; Thomson, 1985). Warthogs transmit ASF through soft ticks bites, with Ornithodoros moubata acting as a vector of the disease among warthogs, but also between warthogs and other suids species, particularly domestic pigs. These ticks are the natural reservoir maintaining the disease (Pereira de Oliveira et al., 2019). In the absence of Ornithodoros ticks, warthogs do not excrete sufficient amount of virus to transmit the disease horizontally to domestic pigs, therefore, the presence of warthogs is not enough to maintain a permanent source of virus in the environment (Ferran Jori \& Bastos, 2009). The bushpig has been proven to be naturally resistant by experimental infection (Oura, Powell, Anderson, \& Parkhouse, 1998). Previous studies suggest that bushpigs could have a potential role in the transmission of ASF (Okoth et al., 2013) because they have been occasionally found carrying the virus in different parts of Africa. Transmission of the virus through direct contact to susceptible domestic pigs has been proven in captivity (Anderson, Hutchings, Mukarati, \& Wilkinson, 1998). However, their potential to maintain ASFV in its natural habitat and its transmission to domestic pigs has not been proven (Ravaomanana et al., 2011; Ståhl et al., 2014).

In Southern and East Africa, the maintenance of ASF in a sylvatic cycle linked to the presence and maintenance of ASF virus in Ornithodoros ticks in warthog burrows, represents a challenge for the development of pig farming in rural areas due to a constant risk of ASF spill over to domestic pigs (Quembo, Jori, Heath, Pérez-Sanchez, \& Vosloo, 2016). This can occur through direct physical or indirect contact between wild 
and domestic suids through the sharing of environmental resources such as soil, forage and water, facilitating disease transmission (Kock, 2005). ASF is a disease of global concern as it has the capacity to spread worldwide and can lead to severe socio-economic impact, both in areas where it is newly introduced and where it is endemic (Chenais et al., 2019). In South Africa ASF is a notifiable disease with a disease-free area and a control area defined in 1935 where ASF has been reported as endemic. Spread of ASF out of the control area should be notified internationally to the OIE and could result in an international ban of pigs and pork trade involving the disease-free area (OIE, 2011).

ASF is endemic in Mozambique, adjacent to areas with extensive subsistence pig farming in South Africa. The first laboratory-confirmed outbreak of ASF in Mozambique was reported in 1960. A number of outbreaks have since been observed around the country, including in the region south of Maputo, within $30 \mathrm{~km}$ of our study site. Though movements of domestic pigs from one province to the other played a role in disease transmission and spread, the sylvatic cycle was considered equally important particularly in the vicinity of conservation areas where warthogs and bushpigs are common (M. L. Penrith et al., 2007).

The complexity in the eco-epidemiology of this multi-host pathogen disease makes it hard to implement disease mitigation strategies. Among other factors, farming practices in neighbouring communities, the distance from the neighbouring community to a protected area (PA), the availability of resources in PAs, and the nature of the fence (surrounding PAs) stimulate wildlife-livestock interactions that promote the introduction and spread of diseases (Kukielka et al., 2016). Cowled and Garner (2008) argued that behaviour, animal density, distribution, contact rate, and habitat connectivity of both the vector and susceptible species are important for understanding how diseases are transmitted between wildlife and livestock. For ASF, the higher the wild suid density within a PA the greater the chances that some of the suids will get into contact, directly or indirectly, with domestic pigs. Also, the further wild suids move from the PA into farmland, the greater the risk of disease transmission. Pech and Mcllroy (1990) argued that the movements of pigs increase the likelihood of contact between infected and uninfected pigs, and thus the spatial extent, and velocity of the spread of a disease.

Fencing has a long history in wildlife conservation and in many cases it has proven to be an effective tool for keeping wildlife out of specific areas, controlling animal movements and disease outbreaks (Durant et al., 2015). Fences are often deleterious to wildlife, preventing access to food and water as well as natural migration, but also to protect wildlife from human threats (Pirie, Thomas, \& Fellowes, 2017). However, given that they undergo changes, fences probably do not work in the same way and with the same efficiency in all cases. Floods, breaks due to wildlife movement and damage due to theft are different factors increasing fence permeability. Therefore a fence requires regular inspection and maintenance (Ferran Jori et al., 2011).

This study aims to provide quantitative information about the potential presence of a sylvatic cycle at the wildlife livestock interface around Ndumo Game Reserve (NGR), which is part of the Lebombo Transfrontier Conservation Area, a transboundary conservation initiative including protected areas from South Africa, Swaziland and Mozambique. NGR is home to warthogs and bushpigs which play a role in maintaining and transmitting livestock diseases (Solenne Costard et al., 2009). Also, it is adjacent to a communal area with a substantial amount of farmed pigs, generating a wildlife-livestock interface. In addition, the reserve is within the boundaries of the ASF control zone in South Africa. That means the area is suspected to have a sylvatic cycle in which Ornithodoro s tick populations colonize warthog burrows, representing a permanent source of ASF. The reserve shares its borders with Mozambique where ASF is considered to be endemic. Understanding the extent to which wild suids from NGR interact with surrounding domestic pigs close to NGR is critical for the surveillance and control of ASF. Therefore, the specific objectives of our study were: i) to estimate the population size of warthog and bushpigs in NGR; ii) to assess the presence of ticks in warthog burrows from NGR; iii) to study the movements of wild suids between NGR and the adjoining farming areas and their potential interactions with domestic pigs.

\section{Methodology}

\subsection{Study Area}


NGR is a 10117 ha wildlife reserve bordering both the Mathenjwa community of Northern KwaZulu Natal Province, South Africa and also Mozambique (Figure 1). The boundary of the reserve is fenced except on its northern side, where the seasonal Usuthu River separates South Africa and Mozambique. There are two seasons: wet (October- March) and dry (April-September) with an average annual rainfall of $638 \mathrm{~mm}$. The mean annual temperature is $21.9 \mathrm{degC}$ with dry season temperatures often reaching well above $40 \mathrm{degC}$. Villages around the eastern, western, and southern boundaries of the reserve are typical of South African communal areas where subsistence farming is the major economic activity. The villagers grow mainly maize and keep livestock which include cattle, goats, pigs, and chickens. Dipping, the driving of cattle through a specially constructed concrete tank with water and an acaricide to control ticks on cattle, is a regular activity in these villages.

NGR is home to a variety of mammals including different species of antelope, black and white rhinos, hippos, crocodiles and both species of wild suids (bushpigs and warthogs). The Usuthu and Pongola Rivers feed the pans (water-logged areas), namely Nyamithi, Banzi, Shokwe, Usuthu, and Pongola pans. Within the game reserve, fence and reserve patrols are a daily activity for field rangers to combat poaching.

The reserve has seven major vegetation types: Western Maputaland Clay Bushveld, Makatini Clay Thicket, Lowveld Riverine Forest; Western Maputaland Sandy Bushveld, Sand Forest, Subtropical Alluvial Vegetation; and Subtropical salt pans (Mucina, Rutherford, \& Powrie, 2006). In order to facilitate interpretation and analysis of the results, only four vegetation types were used after grouping vegetation types with similar physical vegetation structure and plant species: Bushveld, Thicket, Sandveld and Water (Figure 1).

\subsection{Abundance estimation}

\subsubsection{Warthog numbers derived from annual transect counts}

NGR has eight permanent line transects used for annual game counts, ranging from $1.5 \mathrm{~km}$ to $8 \mathrm{~km}$ with a combined length of $50.915 \mathrm{~km}$. The transects cut across the four vegetation types. ArcGIS 10.6 (ESRI, Redmont, California, USA) was used to measure lengths of transects based on their position within different vegetation types (Table 1, supplementary material). These transects were used to conduct annual warthog counts and bushpig track counts. To maximise the accuracy of estimates, the eight transects in NGR were walked 16 times annually, during the dry seasons (April-September) of 2017 and 2018 and using distance sampling methodology. The researcher, together with NGR game scouts and students from Tshwane University of Technology (TUT), conducted the counts in the morning (5-8 am) to maximise chances of detecting warthogs because they are difficult to detect later in the day when they rest in the shade. Two observers, each focusing on one side of the transect, counted warthogs observed and, for each encounter, recorded the coordinates of the observer, distance from observer to animal (r), group size (n), and angle of the animal from the transect $(\Theta)$. In addition, transect count data from 2013 to 2016 were made available for analysis by Ezemvelo KwaZulu Natal Wildlife (EKZNW). The number of warthogs in the reserve was estimated using the Distance sampling software (Distance V8) using the negative exponential cosine model as the detection function. This function computes the likelihood contributions for off-transect sightings distances, scaled appropriately, for use as a distance likelihood. Only those years with consistent and reliable count data that fitted statistical models were used. Warthog transect sightings were mapped according to vegetation types using ArcGIS V10 and recorded in Excel (Microsoft Corporation, 2018) as follows: a) year of transect counts b) transect number $\mathrm{c}$ ) vegetation type in which that observation was made d) length of the transect within that specific habitat e) number of warthogs seen and f) a the number of warthogs per $\mathrm{km}$ of transect. Descriptive analyses and linear mixed effect regression (Pinheiro and Bates, 2006) were performed. Summary statistics, including mean and standard error of the mean (SEM), were computed.

\subsubsection{Bushpig relative abundance using the transects}

Bushpigs are crepuscular and nocturnal and seldom observed. Therefore the only realistic method of assessing bushpig abundance is the use of indirect evidence provided by tracks, as well as photographs obtained by static camera traps. Bushpig track transect counts, using the eight transects used for warthogs, were conducted on a separate occasion (June 2018 to December 2018). In order to maximise statistical reliability, each transect 
was walked 21 times recording bushpig tracks encountered. The researcher was assisted by game scouts with experience in animal tracking. Bushpigs tracks, when compared to those of warthog, have broader hoofs and their claw mark show clearly on the tracks. To avoid the risk of double-counting, tracks were erased using branches. For each observation the following data were entered in MS Excel : date, repetition, transect number, vegetation type, length of that particular vegetation type in a transect, GPS coordinates of where the observation was made, number of tracks and, number of events (an event is a discrete cluster of tracks on a particular transect). Tracks indicated the total count of tracks recorded per event. A linear mixedeffects regression model was performed to predict the mean number of events and tracks based upon habitat (Pinheiro \& Bates, 2006), allowing an assessment of relative bushpig abundance indicators (tracks an events) in each of the four habitat categories in NGR.

\subsubsection{Camera trap surveys}

A pilot study was conducted from May to July 2017 to fine-tune the camera trap data collection method. Twenty four static camera traps were deployed based on field rangers' perception of areas where bushpigs could be found. During the pilot study, the duration of each camera trap placement was variable because NGR has a history of extensive theft of cameras by poachers. Camera traps were removed immediately after signs of human activity were observed near a camera. After the pilot study, 48 camera trap stations were randomly positioned within the four main vegetation types (Fig 1). Camera trap surveys were conducted from February to December 2018. At each camera trap station, a single camera was tied to a tree or stump at bushpig height $(30-50 \mathrm{~cm}$ above the ground) or higher $(150-200 \mathrm{~cm})$ with a downward pointing inclination, depending on the vegetation. Surrounding vegetation that would promote triggering by wind in front of the camera was cleared. Despite the nocturnal behaviour of the target species, camera traps were set to record photographs 24 hours a day. Trophy Cam @ (Bushnell Outdoor Products, USA) cameras had continuous triggering of a one-second interval between consecutive images while ScoutGuard ( $\mathrm{B}$ cameras were set to record $10 \mathrm{~s}$ video footage each time a movement was detected within the distance range $(15 \mathrm{~m})$. The date and time were shown on each photograph/video. The objective was 60 consecutive days periods of observation but the period was sometimes shortened in the case of poacher activity around the camera traps. All images were downloaded from the cameras after which the date and duration of each observation of suids were entered into MS Excel, each record reflecting an event per specific camera trap station (an event is an observation of at least one suid within a single 30-min time interval). The following were recorded a) camera trap station ID b) GPS coordinates of the camera, c) habitat in which the camera trap was installed d) bushpig count (the total number of animals seen for all the pictures taken during one event on a camera trap station) e) duration of each event $f$ ) time duration since the previous event. Wild suid rate is the number of wild suid individuals (bushpig or warthog) photographed per camera day. Likewise, events are the number of events per camera day. Due to the small sample size of suid observations in the sand and bushveld habitats, these two vegetation types were merged into a single category. Log transformation of raw data was performed to obtain a normal-like statistical distribution of abundance values. A 1-way ANOVA was performed for detecting differences in wild suid rate between habitats.

\subsection{Fence Survey}

In February 2018, a pilot fence survey was conducted to identify portions of the fence with holes used by wild suids. We term these holes as sites. The fence was divided into four main sections to relate fence crossings by pigs to the localities of farms. Thirty-two sites were identified on the western part of the reserve, 57 on the South-western side, 46 on the south-eastern and 6 on the eastern side. Two bouts of fence surveys were conducted to identify wild suid activities at the respective sites: the wet season survey was conducted on 27 consecutive days of February 2018 and the dry season survey was conducted in August 2018 for 30 consecutive days. The number and location of all the sites were the same for both surveys. On each day, each site was inspected for the presence of bushpig and/or warthog tracks. Once tracks were observed, the researcher, with the help of experienced tracker game scouts, took note of the species responsible, identity of the site, and the number of tracks counted. For each observed set of tracks, the species was identified, based on the footprints (on a few occasions droppings). Three items were recorded for each site: a) whether 
tracks indicated wild suids crossing the fence (= a crossing event); b) the species of suid; c) an estimate of the number of wild suids that had crossed at that point, based on the tracks leading to and from the site. A crossing event refers to an occasion when one or more warthogs/bushpigs crossed the fence at a specific site. The mean number of crossing events/site/day during a survey $\left(f_{c}\right)$ is the mean daily number of crossing events/site for a specific section of the fence during the survey (Table 5). Similarly, the mean number of wild suids/site/day during a survey $\left(f_{p}\right)$ represents the mean daily number of wild suids/site for a specific section of the fence during the survey (Table 5). Since the statistical distribution of the number of crossings was similar to that described by a negative exponential function, we performed analyses on the natural log-transformed values of $f_{c}$ and $f_{p}$. For detecting differences among the four sections of the fence, a 1-way ANOVA was separately performed on $f_{c}$ as well as on $f_{p}$ classified by fence section. For detecting differences between the dry and wet seasons, a repeated-measures ANOVA was separately performed on $f_{c}$ as well as on $f_{p}$ categorised by season. Standard errors of the estimates (S.E.M.) for the number of wild suids crossing the whole fence each day were generated by performing 1000 bootstrap samples of the observations at each fence site and finding the S.E.M. of the 1000 estimates of the wild suid crossing rate. R V3.4.4 (R Core Team, 2018) was used for all statistical analysis and statistical significance was set for P-value lower or equal to 0.05 .

\subsection{Farmers Interviews}

A structured questionnaire was used to collect data from all smallholder pig farmers within the Mathenjwa community ( $\mathrm{n}=254$ ) from April 2017 to December 2017. The purpose of the interview was to gather information on potential wild-domestic pigs interactions observed by the local rural communities and to gather information on prevalent pig diseases in the area. Pig farmers were identified at dip tanks and interviews were conducted on their farms. The 45 minutes interview comprised of 22 questions administered in the Zulu language by the first author. To ensure that no pig farm was missed, the exhaustive snowball method was used (Etikan, Alkassim, \& Abubakar, 2016). Farmers were asked if they observed wild suids near their farm (Table 6, supplementary material). Observations were clustered into 2 groups of distances from their farms to the observed suids: near $(0-20 \mathrm{~km})$ and far $(>20 \mathrm{~km})$. This clustering represented farmer's opinions on contact rate of wild and domestic pigs from those that are either very close or very far away from the reserve. If any observation was made, they were asked to respond to whether they had seen the suids a) in direct contact with domestic pigs (physical contact) b) on their farms (close to domestic pigs) or c) close to their farms or d) elsewhere. They were also asked to comment on diseases of their domestic pigs and about potential outbreaks of ASF occurring in the area. Farmers were asked if their pigs got sick or died from any disease. If affirmative they provided symptoms. They also were asked to name diseases that were prevalent in the study area.

\subsection{Soft ticks survey}

Warthog burrows within NGR were identified with the assistance of game scouts during their regular patrols. When a warthog burrow was encountered, we looked for signs of activity (tracks and droppings) then GPS coordinates were recorded. A 20 litre bucket was used to collect sand from each burrow which was spread in a thin layer across a large, black plastic sheet in the sun. Due to photophobic nature of soft ticks, the sunlight and warm temperatures encourages Ornithodoros tick movement and facilitates tick detection as well as collection. A minimum period of 30 minutes per burrow was allowed, to ensure that tick movement would be elicited and that all visible ticks were collected (Ferran Jori et al., 2013)

\subsection{Ethics}

The methods used for collecting data from pig farmers were assessed and approved by the University of Pretoria's human ethics committee (EC 161129-084). Permission to conduct the study within the NGR was also obtained from Ezemvelo Kwazulu Natal Wildlife authorities. Verbal consent from the local chief was obtained before project inception. For the interviewees, participation was voluntary, private, and confidential and there was no penalty if they decided not to participate. Written informed consent was obtained from each participant. 


\section{Results}

\section{Wild suid counts derived from transect counts}

\subsubsection{Warthog numbers from distance sampling and habitat preference}

Using the Distance software, data for the years, 2013-2018 were analysed. The years 2013 and 2018 produced interpretable results. The estimation of the number of warthogs in NGR were $n=632,95 \%$ confidence interval $=[490,815]_{95 \%}$ and $n=383, \mathrm{CI}=[271,541]_{95 \%}$ respectively. This suggests a population ranging between 400 and 500 warthogs, i.e. $3-5$ individuals $/ \mathrm{km}^{2}$ in NGR. Table 2 shows the raw counts of warthogs along the transects for each year. Warthogs had a significant preference for water areas compared to other vegetation types (1-way ANOVA $\mathrm{P}=0.002)$.

\subsubsection{Bushpig relative abundance and habitat preference using line transect counts}

Linear mixed-effects ANOVA indicate that thickets (15.601 tracks $/ \mathrm{km}$, Table 3) had by far the highest density of bushpig tracks when compared to Sandveld $(2.566$ tracks $/ \mathrm{km})$ and water areas $(5.374$ tracks $/ \mathrm{km})$. The trend was similar for both events data as well as for the tracks data. Bushveld areas had no bushpig tracks.

\subsection{Wild suid abundance estimation using camera traps}

Forty-eight camera traps were installed in 4 different vegetation types for a total of 1383 days. Bushpigs $(n=483)$ were observed more frequently than warthogs $(n=304)$. Similarly, the mean observation rate was higher for bushpigs (0.3518 animal/day, Table 5) than for warthogs (0.221 animal/day, Table 4). This suggests that bushpigs are at least as common as warthogs in NGR.

\subsubsection{Warthogs}

Although the camera-derived results suggested that warthogs were more common in the sand vegetation (0.536 animals/camera day; 0.268 events/camera day, Table 4 ), the effect was not statistically significant due to low numbers of warthog recorded.

\subsubsection{Bushpigs}

Even though camera data suggested that bushpigs preferred water areas to other habitats, this was not statistically significant due to a relatively small sample size of bushpigs observed. The findings were consistent with events (Table 4).

\subsection{Tick presence in warthog burrows}

Despite intensive sampling, no soft ticks were recovered from any of the 35 warthog burrows in NGR (Figure $1)$.

\subsection{Movements of wild suids across NGR boundaries}

Pig count data: The mean number of bushpigs crossing the fence in wet season (0.56 pigs/day, Table 5$)$ was 11 times lower than the mean number observed in dry season (6.348 pigs/day, Table 5$)$ and this difference was statistically significant $(\mathrm{P}<0.0001)$. Similarly, the mean number of warthogs crossing the fence was significantly lower during the wet season (10.26 pigs/day, Table 5) compared to the dry season (15.4 pigs/day, Table 5) $(\mathrm{P}=0.03)$.

Crossing event data: Bushpigs crossed the reserve fence at a significantly higher rate (0.0592 events/site/day, Table 5) $(\mathrm{P}<0.0001)$ during the dry season survey than during the wet season survey $(0.0066$ events/site/day). Warthogs had a similar trend as bushpigs. However, there was no seasonal effect in the number of warthog crossing events (0.036 events/site/day,) during the dry season survey and (0.028 events/site/day) in wet season survey (Table 5). Bushpigs crossed the western section at a significantly higher rate than the southeastern section in both dry $(1.592$ pigs/day $)(\mathrm{P}<0.0001)$ and wet $(0.1389$ pigs/day $)(\mathrm{P}=0.0315)$ seasons. In the wet season no bushpigs crossed through the eastern fence. Warthogs showed a similar trend although the differences are not statistically significant (Table 5). 


\subsection{Reports of wild suid presence in surrounding pig farms}

Most pig farms were concentrated adjacent to the western (78\%) and south-western (13\%) sections of the fence. While some farms were also located in proximity of the south-eastern fence section (9\%), the eastern section had no adjacent farms. The highest number of domestic pigs $(\mathrm{n}=631)$ was located close to the western section of the fence while a considerably smaller number $(n=172)$ was found on the south-western section of the fence (Figure 1).

Among the 254 pig farmers, eight reported bushpigs near their households (20km radius) while three reported to have seen warthogs. None of them reported any direct interaction between those wild suid species and their domestic pigs. Bushpig sightings were reported as far as $19 \mathrm{~km}$ from the fence while for warthogs the furthest was $8 \mathrm{~km}$ (Fig 2).

Pig farmers who reported bushpigs near their households were located adjacent to the western, southwestern, and south-eastern section of the fence, whereas those who had seen warthogs tended to be more evenly distributed adjacent the western and south-eastern section of the fence. (Fig 2). None of the farmers reported disease or disease symptoms compatible with ASF outbreaks.

\section{Discussion}

Warthogs and bushpigs are common in the study area. Annual transects counts in NGR revealed a warthog density of 3-5 individuals $/ \mathrm{km}^{2}$, with a total population of 400-500 warthogs in the area. These estimates fall on the lower end of population densities found by Cumming (1975) who reported that in Africa warthog densities range from 1-15 individuals $/ \mathrm{km}^{2}$. This could be partly explained by their preference for open savannah (Deribe, Bekele, \& Balakrishnan, 2008), instead of the bush thicket that is common at NGR. The camera trap survey indicated that NGR has a significant bushpig population, which may be similar to warthogs in numbers. This approach was useful in detecting the abundant bushpig population which had not been recorded using the diurnal line transects. Most of the bushpig recorded on camera traps (0.515 animals/ camera day) were found in habitats close to water, consistent with the observations of different authors who noted that bushpigs are water-dependent (J. Kingdon, 2014; Seydack, 2017). Warthogs (0.536 animals/ camera day) on the other hand, were also found in sandy environments. Therefore, NGR provides a good habitat for both wild suids.

Movements of both wild and domestic suids can facilitate direct or indirect interactions with domestic pigs as well as ASF transmission at the interface of a protected area (Arias, Jurado, Gallardo, Fernández-Pinero, \& Sanchez-Vizcaino, 2018).

Both wild suid species regularly crossed the game fence, moving into adjacent farmland. Standard wire or wire-mesh fencing is not very efficient to contain suiform species and warthogs are often reported to escape from other protected areas by digging under fences (Ferran Jori et al., 2011; Swanepoel, Schulze, \& Cumming, 2016). Therefore, in cases where it is important to contain wild suids in conservation areas, we recommend to consider using other kinds of barriers such as wild boar proof fences (EFSA, 2014; Satheeshkumar, Manjusha, Pillai, \& Kumar, 2012).

In our study area, crossings were more common during the dry season for both bushpigs (6.35 bushpigs/day) and warthogs (15.4 warthogs/day). The high number of fence crossings represents a challenge in the management of diseases in domestic pigs. This is because, in the farming area (as in many African rural areas) a considerable population of domestic pigs is left free-ranging, which increases the chances of direct and indirect interactions between wild and domestic suids and disease transmission (F Jori, Payne, Stahl, Nava, \& Rossi, 2018). This risk is exacerbated by the fact that most crossings were observed on the western side of the reserve where the highest number of pigs farms are located. A possible explanation for more crossings on the western section could be that this terrain is mountainous and it has a moister thicket vegetation, providing a more suitable habitat for a shy species such as the bushpig (Flamand, Horak, \& Boomker, 1991; Ferran Jori \& Bastos, 2009). This habitat also provides the suids with fruit and bulbs (Nyafu, 2009) particularly during the dry season when resources in the game reserve are scarce. The farms therefore have the potential 
for high levels of direct or indirect wild-domestic and domestic-domestic pig interactions, facilitating the transmission of shared pathogens, such as ASF. Despite limited veterinary research on the pathogenic burden of wild African pigs compared to the Eurasian wild boar (Sus scrofa), warthogs and bushpigs are known to be carriers of ASF as well as other pathogens such as trichinella, bovine tuberculosis and several porcine viruses that could be transmitted to domestic pigs sharing the same environment (F Jori et al., 2018).

Similar to other studies, some farmers $(n=11)$ reported to have seen at least one of the wild suid species outside the reserve (Kukielka et al., 2016), but none of the suids was observed interacting with domestic pigs. While natural hybridization between domestic pigs and warthogs has not been reported, there are a number of reports of cross-breeding between bushpigs and domestic pigs (Ferran Jori \& Bastos, 2009; Jonathan Kingdon, 2015). We assume than while interactions could occur, they are not necessarily observed due to the elusive and nocturnal behaviour of bushpigs (Payne et al., 2018). Incursions of bushpigs in farming areas are likely to occur at night and warthogs might have human avoidance behaviour (Kassilly, Tsingalia, \& Gossow, 2008). Therefore, questionnaires alone are not the best method for conclusions on potential nocturnal interactions and other methodologies such as radio tracking and setting up camera traps near pigsties should be considered.

In many African rural areas, a considerable number of domestic pigs are free-ranging (Nantima et al., 2015; M.-L. Penrith, Vosloo, Jori, \& Bastos, 2013; Quembo et al., 2016), increasing the chances of direct and indirect interactions between wild and domestic suids interactions and potential pathogen transmission (F Jori et al., 2018; M.-L. Penrith et al., 2013). Even though the sharing of the same habitat and resources represents an ideal situation for the transmission of pathogens between wild suids and domestic pigs (Barth et al., 2018), in our study we could not find any indication suggesting that NGR currently harbours a sylvatic cycle that would allow wild suid species to act as carriers of ASF. We did not find any evidence of Ornithodorostick infestation among our surveyed burrows $(n=35)$, suggesting that the tick reservoir is currently unlikely to be present in NGR and a permanent source of ASF virus is not maintained in the reserve despite the presence of warthogs and bushpigs. These findings are similar to similar studies in Mkuze Game Reserve (approximately $100 \mathrm{~km}$ south of NGR) who inspected 98 warthog burrows and collected ticks (Arnot, du Toit, \& Bastos, 2009).

The apparent absence of a sylvatic cycle in NGR is consistent with the fact that none of the farmers interviewed was concerned with severe disease outbreaks compatible with regular ASF. Given the importance of the sylvatic cycle in Mozambique and the observations of some ASF outbreaks on the Mozambican side close to NGR (M.-L. Penrith et al., 2013), further research should be undertaken on a larger number of burrows in order to confirm this suspicion. Another aspect that should be explored further is a survey of ASF antibodies in wild pigs and domestic pig populations living at the interface of the NGR. Indeed, an absence of circulating antibodies in these populations would be a good indicator that ASF virus is not being maintained in this study area.

The combination of an endemic ASF status in Mozambique (northern boundary of NGR), the presence of significant numbers of warthog and bushpig within NGR, the regular movements of both species between NGR and the surrounding farmland, suggest that strong veterinary surveillance and management remains necessary to identify potential infectious disease transmission to the local pig population, and which can act as a sentinel population.

\section{Conclusion}

We investigated the interface between wild and domestic pigs and the potential presence of a sylvatic cycle in an African protected area. Both warthogs and bushpigs are common in NGR and they often move out of the park, sharing home ranges and resources with domestic pigs, particularly in the dry season. Therefore fencing should not be the method of choice to prevent transmission from potentially infected wild suids to neighbouring pig farming areas since they are prolific diggers. Despite many opportunities for wild-domestic interactions, it seems unlikely that the wild suids currently transmit ASF to domestic pigs as no ticks where found in warthog burrows and surrounding pig farmers were not familiar with ASF outbreaks in their area. 
Further research should explore a larger number of warthogs burrows to confirm absence of ticks and potential antibodies against ASF and other diseases should be monitored in pigs and wild suids which are potentially exposed to ASF. An awareness program among smallholder farmers is also encouraged particularly targeting the western and southern sections that could potentially have a high burden of contact between wild and domestic pigs. Confining pigs during periods of high potential interactions (at night and/or in dry season) is also recommended since full-time penning is expensive and impractical. Considering the proximity of the Mozambican border, regular surveillance of wild and domestic suids is equally important for monitoring potential incursions of ASF in this high risk area.

\section{Conflict of interest}

There was no conflict of interest. None of the authors received any funding from Ezemvelo Kwazulu-Natal Wildlife to do the work.

\section{Acknowledgements}

We acknowledge funding from the American Society for Mammalogists (ASM), National Research Foundation (NRF), Association for African Universities (AAU) and Belgian Technical Cooperation ( BTC). We gratefully acknowledge the Ezemvelo Kwazulu-Natal Wildlife ecologist, Catherine Hanekom for availing previous transect count data, the reserve managers Amos Tembe and Andile Mhlongo of Ezemvelo KwazuluNatal Wildlife for all the logistical support within NGR. Special mention goes to the EKZN Wildlife Ndumo field rangers for their expertise in the field. We wish to thank all the pig farmers for willingly supplying information needed for this particular study. Last but not least we would like to extend our gratitude to Marinda Cilliers for all the logistical support.

\section{References}

Anderson, E., Hutchings, G., Mukarati, N., \& Wilkinson, P. (1998). African swine fever virus infection of the bushpig (Potamochoerus porcus) and its significance in the epidemiology of the disease. Veterinary microbiology, 62 (1), 1-15.

Arias, M., Jurado, C., Gallardo, C., Fernandez-Pinero, J., \& Sanchez-Vizcaino, J. (2018). Gaps in African swine fever: Analysis and priorities. Transboundary and emerging diseases, 65 , 235-247.

Arnot, L., du Toit, J., \& Bastos, A. (2009). Molecular monitoring of African swine fever control areas: adult-tick targeted re-evaluation of Mkuze Game Reserve, South Africa. Onderstepoort Journal of Veterinary Research, 76,385 .

Barth, S. A., Blome, S., Cornelis, D., Pietschmann, J., Laval, M., Maestrini, O., . . . Menge, C. (2018). Faecal Escherichia coli as biological indicator of spatial interaction between domestic pigs and wild boar (Sus scrofa) in Corsica. Transboundary and emerging diseases, 65 (3), 746-757.

Chenais, E., Depner, K., Guberti, V., Dietze, K., Viltrop, A., \& Stahl, K. (2019). Epidemiological considerations on African swine fever in Europe 2014-2018. Porcine health management, 5 (1), 1-10.

Chenais, E., Stahl, K., Guberti, V., \& Depner, K. (2018). Identification of Wild Boar-Habitat Epidemiologic Cycle in African Swine Fever Epizootic. Emerging infectious diseases, 24 (4), 810-812. doi:10.3201/eid2404.172127

Costard, S., Mur, L., Lubroth, J., Sanchez-Vizcaino, J., \& Pfeiffer, D. U. (2013). Epidemiology of African swine fever virus. Virus research, 173 (1), 191-197.

Costard, S., Wieland, B., De Glanville, W., Jori, F., Rowlands, R., Vosloo, W., . . . Dixon, L. K. (2009). African swine fever: how can global spread be prevented? Philosophical Transactions of the Royal Society B: Biological Sciences, 364 (1530), 2683-2696.

Cowled, B., \& Garner, G. (2008). A review of geospatial and ecological factors affecting disease spread in wild pigs: considerations for models of foot-and-mouth disease spread.Preventive veterinary medicine, 87 
(3-4), 197-212.

Cumming, D. (1975). A field study of the ecology \& behaviour of warthog. National Museums and Monuments of Rhodesia, Salisbury, Rhodesia .

Deribe, E., Bekele, A., \& Balakrishnan, M. (2008). Population status and diurnal activity patterns of the common warthog (Phacochoerus africanus) in the Bale Mountains National Park, Ethiopia. International Journal of Ecology and Environmental Sciences, 34 (2), 91-97.

Durant, S. M., Becker, M. S., Creel, S., Bashir, S., Dickman, A. J., Beudels-Jamar, R. C., . . . Wittemyer, G. (2015). Developing fencing policies for dryland ecosystems. Journal of Applied Ecology, 52 (3), 544-551.

EFSA. (2014). Evaluation of possible mitigation measures to prevent introduction and spread of African swine fever virus through wild boar. EFSA Journal, 12 (3), 3616.

Etikan, I., Alkassim, R., \& Abubakar, S. (2016). Comparision of snowball sampling and sequential sampling technique. Biometrics and Biostatistics International Journal, 3 (1), 55.

Flamand, J., Horak, I. G., \& Boomker, J. D. F. (1991). Ixodid ticks and lice infesting red duikers and bushpigs in north-eastern Natal. Onderstepoort Journal of Veterinary Research, 58 , 281-284.

Jori, F., \& Bastos, A. D. (2009). Role of wild suids in the epidemiology of African swine fever.EcoHealth, 6 (2), 296-310.

Jori, F., Brahmbhatt, D., Fosgate, G. T., Thompson, P. N., Budke, C., Ward, M. P., . . . Gummow, B. (2011). A questionnaire-based evaluation of the veterinary cordon fence separating wildlife and livestock along the boundary of the Kruger National Park, South Africa. Preventive veterinary medicine, 100 (3-4), $210-220$.

Jori, F., Payne, A., Stahl, A., Nava, A., \& Rossi, S. (2018). Wild and feral pigs: disease transmission at the interface between wild and domestic pig species in the old and the new world. Ecology, Evolution and Management of Wild Pigs and Peccaries , 388-403.

Jori, F., Vial, L., Penrith, M.-L., Perez-Sanchez, R., Etter, E., Albina, E., . . . Roger, F. (2013). Review of the sylvatic cycle of African swine fever in sub-Saharan Africa and the Indian ocean. Virus research, 173 (1), 212-227.

Kassilly, F. N., Tsingalia, H. M., \& Gossow, H. (2008). Mitigating human-wildlife conflicts through wildlife fencing: a Kenyan case study. Wildlife Biology in Practice .

Kingdon, J. (2014). Mammals of Africa: Volume III: Rodents, Hares and Rabbits : Bloomsbury Publishing.

Kingdon, J. (2015). The Kingdon field guide to African mammals : Bloomsbury Publishing.

Kock, R. (2005). What is this infamous "wildlife/livestock disease interface?" A review of current knowledge for the African continent. Conservation and development interventions at the wildlife/livestock interface: implications for wildlife, livestock and human health, 30 , 1-13.

Kukielka, E. A., Jori, F., Martinez-Lopez, B., Chenais, E., Masembe, C., Chavernac, D., \& Stahl, K. (2016). Wild and domestic pig interactions at the wildlife-livestock interface of Murchison Falls national Park, Uganda, and the potential association with African swine fever outbreaks. Frontiers in veterinary science, 3,31 .

Mucina, L., Rutherford, M. C., \& Powrie, L. W. (2006). Vegetation Atlas of South Africa, Lesotho and Swaziland. The Vegetation of South Africa, Lesotho and Swaziland'.(Eds L. Mucina and MC Rutherford.) pp , 748-789.

Nantima, N., Ocaido, M., Davies, J., Dione, M., Okoth, E., Mugisha, A., \& Bishop, R. (2015). Characterization of smallholder pig production systems in four districts along the Uganda-Kenya border. Livestock Research for Rural Development, 27 (8). 
Nyafu, K. (2009). Warthog as an introduced species in the Eastern Cape. (Masters). Nelson Mandela Metropolitan University, South Africa.

OIE. (2011). Terrestrial Animal Health Code. Zoning and compartmentalisation. World Health Organisation.

Okoth, E., Gallardo, C., Macharia, J. M., Omore, A., Pelayo, V., Bulimo, D., . . . Lekolol, I. (2013). Comparison of African swine fever virus prevalence and risk in two contrasting pig-farming systems in South-west and Central Kenya.Preventive veterinary medicine, 110 (2), 198-205.

Oura, C., Powell, P., Anderson, E., \& Parkhouse, R. (1998). The pathogenesis of African swine fever in the resistant bushpig. Journal of General Virology, 79 (6), 1439-1443.

Payne, A., Ogweng, P., Ojok, A., Etter, E., Gilot-Fromont, E., Masembe, C., . . . Jori, F. (2018). Comparison of three methods to assess the potential for bushpig-domestic pig interactions at the wildlifelivestock interface in Uganda.Frontiers in veterinary science, 5, 295.

Pech, R. P., \& McIlroy, J. (1990). A model of the velocity of advance of foot and mouth disease in feral pigs. Journal of Applied Ecology, 635-650.

Penrith, M.-L., Vosloo, W., Jori, F., \& Bastos, A. D. (2013). African swine fever virus eradication in Africa. Virus research, 173 (1), 228-246.

Penrith, M. L., Pereira, C. L., Da Silva, M. L., Quembo, C., Nhamusso, A., \& Banze, J. (2007). African swine fever in Mozambique: review, risk factors and considerations for control. Onderstepoort Journal of Veterinary Research, 74 (2), 149-160.

Pereira de Oliveira, R., Hutet, E., Paboeuf, F., Duhayon, M., Boinas, F., Perez de Leon, A., . . . Le Potier, M.-F. (2019). Comparative vector competence of the Afrotropical soft tick Ornithodoros moubata and Palearctic species, O. erraticus and O. verrucosus, for African swine fever virus strains circulating in Eurasia. PloS one, 14 (11), e0225657.

Pinheiro, J., \& Bates, D. (2006). Mixed-effects models in S and S-PLUS : Springer Science \& Business Media.

Pirie, T. J., Thomas, R. L., \& Fellowes, M. D. (2017). Game fence presence and permeability influences the local movement and distribution of South African mammals.African Zoology, 52 (4), 217-227.

Plowright, W. (1981). African swine fever. Infectious diseases of wild mammals, 178-190.

Quembo, C. J., Jori, F., Heath, L., Perez-Sanchez, R., \& Vosloo, W. (2016). Investigation into the Epidemiology of African Swine Fever Virus at the Wildlife-Domestic Interface of the Gorongosa National Park, Central Mozambique.Transboundary and emerging diseases, 63 (4), 443-451.

Ravaomanana, J., Jori, F., Vial, L., Perez-Sanchez, R., Blanco, E., Michaud, V., \& Roger, F. (2011). Assessment of interactions between African swine fever virus, bushpigs (Potamochoerus larvatus), Ornithodoros ticks and domestic pigs in north-western Madagascar. Transboundary and emerging diseases, 58 (3), 247-254.

Satheeshkumar, P., Manjusha, U., Pillai, N., \& Kumar, D. (2012). Wild boars: is elimination the way forward? Current Science, 102 (1), 14.

Seydack, A. (2017). Bushpig Potamochoerus larvatus (F. Cuvier, 1822). South African National Biodiversity Institute and Endangered Wildlife Trust, South Africa., Volume 3(1), 122-133.

Stahl, K., Ogweng, P., Okoth, E., Aliro, T., Muhangi, D., LeBlanc, N., . . . Rasmussen, H. (2014). Understanding the dynamics and spread of African swine fever virus at the wildlife-livestock interface: insights into the potential role of the bushpig, Potamochoerus larvatus. Suiform Soundings, 13 (1), 24-28.

Swanepoel, M., Schulze, E., \& Cumming, D. (2016). A conservation assessment of Phacochoerus africanus. The Red List of mammals of South Africa, Swaziland and Lesotho. Pretoria, South Africa: South African National Biodiversity Institute and Endangered Wildlife Trust . 
Thomson, G. (1985). The epidemiology of African swine fever: the role of free-living hosts in Africa. Onderstepoort Journal of Veterinary Research, 52 (3), 201-209.

Venter, J., Ehlers Smith, Y., \& Seydack, A. (2016). A conservation assessment of Potamochoerus larvatus. In The Red List of Mammals of South Africa, Swaziland and Lesotho(pp. 5): South African National Biodiversity Institute and Endangered Wildlife Trust ....
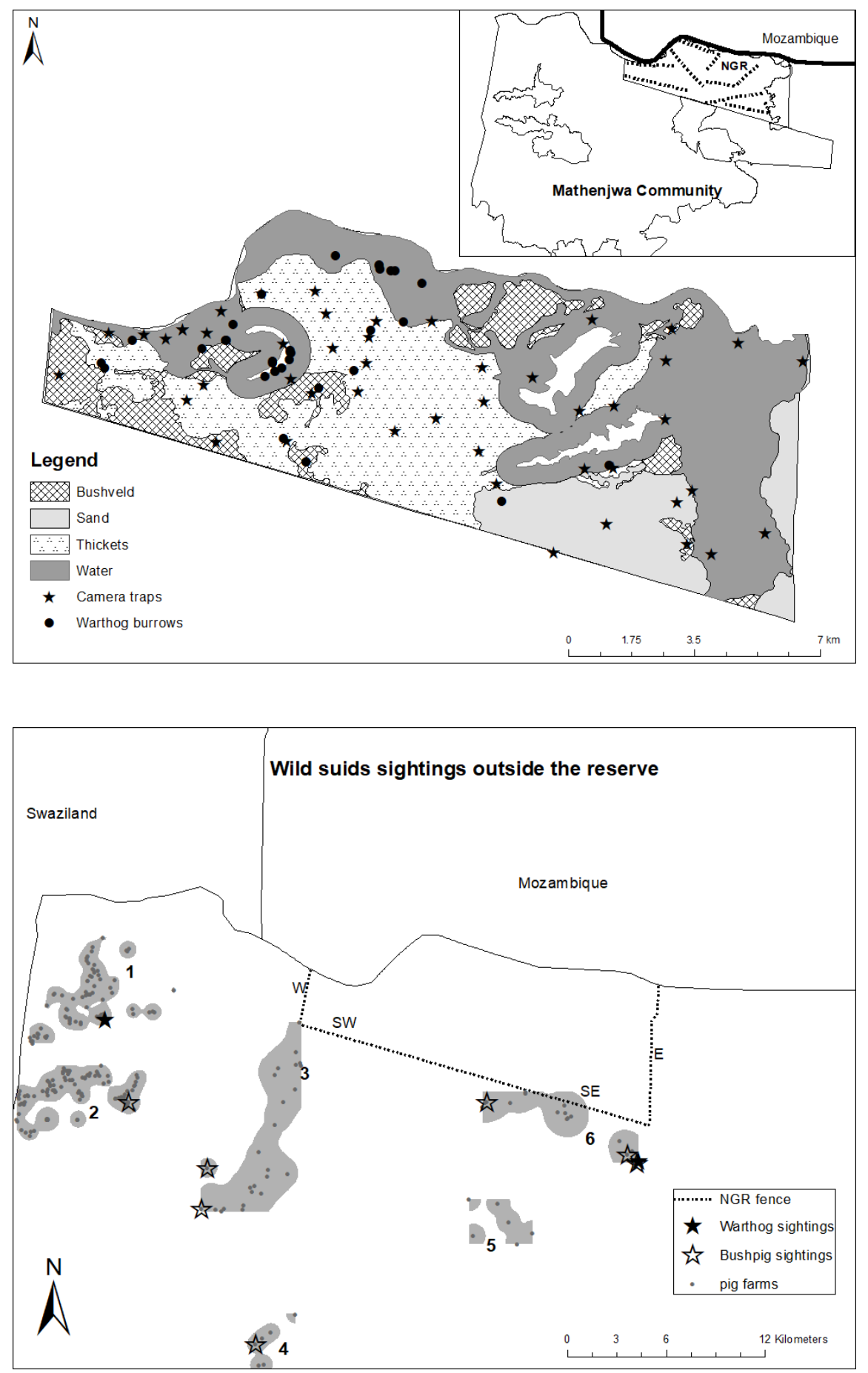


\section{Hosted file}

Table 2.pdf available at https://authorea.com/users/369506/articles/488325-do-wild-suidsfrom-ndumo-game-reserve-south-africa-play-a-role-in-the-maintenance-and-transmission-ofafrican-swine-fever-to-domestic-pigs

\section{Hosted file}

Table 3.pdf available at https://authorea.com/users/369506/articles/488325-do-wild-suidsfrom-ndumo-game-reserve-south-africa-play-a-role-in-the-maintenance-and-transmission-ofafrican-swine-fever-to-domestic-pigs

\section{Hosted file}

Table 4.pdf available at https://authorea.com/users/369506/articles/488325-do-wild-suidsfrom-ndumo-game-reserve-south-africa-play-a-role-in-the-maintenance-and-transmission-ofafrican-swine-fever-to-domestic-pigs

\section{Hosted file}

Table 5.pdf available at https://authorea.com/users/369506/articles/488325-do-wild-suidsfrom-ndumo-game-reserve-south-africa-play-a-role-in-the-maintenance-and-transmission-ofafrican-swine-fever-to-domestic-pigs 